\title{
Pediatric Adenocarcinoma in Korea: A Multicenter Study
}

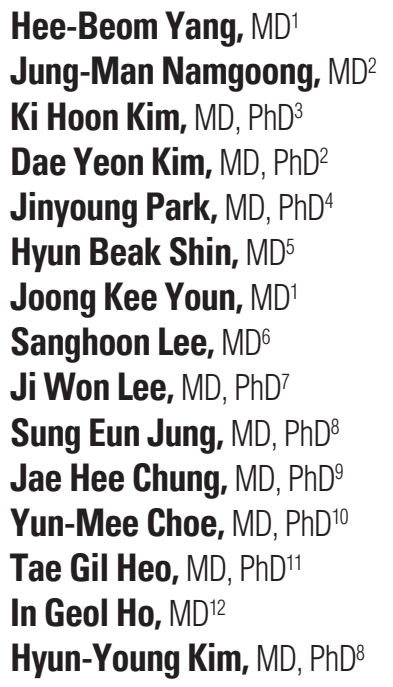

${ }^{*} A$ list of author's affiliations appears at the end of the paper.

Correspondence: Hyun-Young Kim, MD, PhD Department of Pediatric Surgery, Seoul National University College of Medicine, 101 Daehak-ro, Jongno-gu, Seoul 03080, Korea

Tel: 82-2-2072-2478

Fax: 82-2-747-5130

E-mail: spkhy02@snu.ac.kr

Received March 13, 2019

Accepted May 31, 2019

Published Online June 3, 2019

*Hee-Beom Yang and Jung-Man Namgoong contributed equally to this work.

\begin{abstract}
Purpose
Adenocarcinoma is an extremely rare malignancy in the pediatric population. Research regarding pediatric adenocarcinoma is very rare in Korea. This study aimed to investigate the clinical features of pediatric adenocarcinomas of various primary organ sites in Korea.
\end{abstract}

\section{Materials and Methods}

Pediatric patients under 18 years, diagnosed with adenocarcinoma of various sites between January 1995 and December 2016, were included. We retrospectively reviewed patient and tumor characteristics and calculated survival estimates, reported as 5-year survival rate and $95 \%$ confidence interval.

\section{Results}

Of 80 patients (median age, 15 years; range, 10 to 17 years), 37 (46.3\%) were men, and $24(30 \%)$ had a family history of cancer or underlying disease relevant to malignancy. The cancer locations were the colon and rectum $(n=32)$, ovaries $(n=18)$, stomach $(n=15)$, lung $(n=4)$, small bowel $(n=1)$, and other sites $(n=10)$. Totally, $54.8 \%$ patients $(42 / 77)$ had stage 3 or 4 disease. The median follow-up period was 2.0 years (range, 0 to 20.4). The 5-year overall survival estimate for all patients, and for those with stomach, colorectal, ovarian, and other cancer sites were $57.9 \% \pm 11.5 \%, 58.2 \% \pm 25.7 \%, 41.5 \% \pm 18.2 \%, 87.5 \% \pm 16.2 \%$, and $64.0 \% \pm 34.4 \%$, respectively. The 5 -year survival rate differed significantly between categories of adenocarcinomas into gastrointestinal (GI) (44.7\%) and non-Gl adenocarcinomas $(78.8 \%)(p=0.007)$. The 5 -year survival rate also differed significantly according to carcinoembryonic antigen level $(69.3 \%$ in $<3 \mathrm{ng} / \mathrm{mL}, 23.8 \%$ in $>3 \mathrm{ng} / \mathrm{mL} ; \mathrm{p}<0.001)$.

\section{Conclusion}

In pediatric patients, adenocarcinomas arise from various organs and are often diagnosed at advanced stages. Large, prospective studies for their accurate clinical characteristics and prognostic factors are needed.

\section{Introduction}

Among childhood cancers, epithelial carcinoma accounts for a very small proportion; among this, adenocarcinoma (AC) is extremely rare [1]. According to a study that analyzed the Korean childhood cancer using the Korea Central Cancer Registry in 1999-2011, similar results were shown [2]. A single cancer center series showed that gastric cancer (GC)
Key words

Adenocarcinoma, Pediatrics, Rare tumor 
rarely considered as a differential diagnosis in pediatric patients [8]. Approximately $60 \%-80 \%$ of CRC cases in children or adolescents are detected at advanced stages [9]. The clinical course of CRC and patients' characteristics are not well described, and the prognosis is known to be poor due to delayed diagnosis [10]. Pathologic features of AC may differ between adult and pediatric patients; however, these features have not been thoroughly identified. AC management in the pediatric population is consistent with that for adults [11], and has been reported in stomach, small bowel, and lung cancer studies [3,12-17]. For CRC, there are a few reports with $>10$ patients $[8,10,18]$, with one article reporting the clinicopathologic features of $74 \mathrm{CRC}$ patients aged $<18$ years [8]. However, the largest number of pediatric GC patients reported in the medical literature in English was 5 [3], and OC alone has rarely been analyzed. Therefore, this study aimed to analyze the clinicopathologic features and prognosis of AC in Korean pediatric AC patients through a multicenter and large data research.

\section{Materials and Methods}

\section{Patients and samples}

This study, conducted amongst pediatric patients diagnosed with AC between January 1995 and December 2016 in 10 hospitals in Korea, included only patients aged $<18$ years at diagnosis. Members of the Korean Association of Pediatric Surgeons retrospectively retrieved patients' data from medical records on sex, age at diagnosis, symptom duration, and family history of cancer, underlying disease, tumor location, tumor size, tumor marker, and pathologic results including resection margin, chemotherapy, radiation therapy (RT), last follow-up date, date of death, recurrence, and mortality. In total, data from 100 patient records were retrieved from 11 centers (of 40), and data from 20 patient records were excluded (18 were aged $\geq 18$ years and two lacked basic information). Finally, from 10 centers, 80 patients with pediatric GC, CRC, OC, lung cancer, small bowel cancer, and any other ACs were included. ACs of secondary neoplasm after treatment of primary cancer were also enrolled in this study. Any cancer occurring in relatives within two generations, including fathers, grandmothers, cousins, or uncles, was considered a positive family history. Symptom duration was defined as the period from initial symptom onset to diagnosis. Tumor size was defined as the longest diameter from the gross pathologic report. Resection margins were reviewed through microscopic pathologic reports and operation records. Pathologic stages were converted to American Joint Commit-
Table 1. Clinical characteristics of all patients

\begin{tabular}{|c|c|}
\hline & No. $(\%)(n=80)$ \\
\hline \multicolumn{2}{|l|}{ Location } \\
\hline Stomach & $15(18.8)$ \\
\hline Colon & $32(40.0)$ \\
\hline Ovary & $18(22.5)$ \\
\hline Lung & $4(5.0)$ \\
\hline Small bowel & $1(1.3)$ \\
\hline Others & $10(12.5)$ \\
\hline Head and neck & 3 \\
\hline Unknown origin & 3 \\
\hline Bile duct & 1 \\
\hline Pancreas & 1 \\
\hline Cervix & 1 \\
\hline Urinary bladder & 1 \\
\hline Male sex & $37(46.3)$ \\
\hline Age, median (range, yr) & $15(10-17)$ \\
\hline $10-13$ & 19 \\
\hline $14-15$ & 28 \\
\hline $16-17$ & 33 \\
\hline Symptom duration, median (range, mo) & $1.8(0.2-34.4)$ \\
\hline$<2$ & 36 \\
\hline$>2$ & 33 \\
\hline \multicolumn{2}{|l|}{ Stage } \\
\hline 1 & $27(35.1)$ \\
\hline 2 & $8(10.4)$ \\
\hline 3 & $12(15.6)$ \\
\hline 4 & $30(39.0)$ \\
\hline \multicolumn{2}{|l|}{ Operation } \\
\hline R0 & $46(59.7)$ \\
\hline R1 & $3(3.9)$ \\
\hline R2 & $1(1.3)$ \\
\hline Palliative & $16(20.8)$ \\
\hline Not done & $11(14.3)$ \\
\hline Chemotherapy & $49(61.3)$ \\
\hline Radiation therapy & $10(12.5)$ \\
\hline Follow-up period, median (range, yr) & $2.0(0-20.4)$ \\
\hline Recurrence & $11(22.0)$ \\
\hline 5-Year survival rate $(\%)$ & 57.9 \\
\hline
\end{tabular}

tee on Cancer 7th edition stages based on tumor invasion depth and the number of lymph nodes showing metastasis. Patients who received neoadjuvant, adjuvant, and palliative chemotherapy were included. The last follow-up was defined as the last outpatient visit. Recurrence was calculated only in patients undergoing curative intent surgery. The survival period was defined as the interval from AC diagnosis to allcause death.

Treatment was performed according to the general cancer treatment principles applied for adults. In stage 4 patients with distant metastasis, curative intent surgery was not per- 
Table 2. Detailed locations and symptoms of each type of cancer

\begin{tabular}{|c|c|c|c|c|c|c|}
\hline & $\begin{array}{l}\text { Stomach } \\
(\mathrm{n}=15)\end{array}$ & $\begin{array}{l}\text { Colon } \\
(n=32)\end{array}$ & $\begin{array}{l}\text { Ovarian } \\
(n=18)\end{array}$ & $\begin{array}{l}\text { Lung } \\
(n=4)\end{array}$ & $\begin{array}{l}\text { Small bowel } \\
\qquad(n=1)\end{array}$ & Others $^{\text {a) }}$ \\
\hline \multirow[t]{10}{*}{ Location } & 8 Body & 7 Rt. & 11 Rt. & 2 Rt. & 1 Jejunum & 1 Nasal cavity \\
\hline & 3 Antrum & 4 Trans & $7 \mathrm{Lt}$. & $1 \mathrm{Lt}$ & & 1 Oral cavity \\
\hline & 4 Multiple & $5 \mathrm{Lt}$. & & & & 1 Parotid gland \\
\hline & $4 \mathrm{LC}$ & 8 Sigmoid & & & & 1 Pancreas tail \\
\hline & $7 \mathrm{GC}$ & 3 Rectum & & & & 1 Bone marrow \\
\hline & 2 Encircle & 3 Multiple & & & & 1 Spine \\
\hline & & & & & & 1 Brain \\
\hline & & & & & & 1 Uterine cervix \\
\hline & & & & & & 1 Urinary bladder \\
\hline & & & & & & 1 Bile duct, B8 \\
\hline \multirow[t]{9}{*}{ Symptoms ${ }^{\text {b) }}$} & $\begin{array}{l}9 \text { Abdominal } \\
\text { pain }\end{array}$ & $\begin{array}{l}20 \text { Abdominal } \\
\text { pain }\end{array}$ & $\begin{array}{l}13 \text { Abdominal } \\
\text { distension }\end{array}$ & 1 Cough & $\begin{array}{l}1 \text { Abdominal } \\
\text { pain }\end{array}$ & Nasal obstruction \\
\hline & 4 Indigestion & 7 Hematochezia & 2 Abdominal pain & 1 Hemoptysis & 1 Weight loss & Incidental mass \\
\hline & 2 Vomiting & $\begin{array}{l}7 \text { Bowel habit } \\
\text { change }\end{array}$ & 2 Dyspnea & 1 Weight loss & & Infra-auricular pain \\
\hline & 1 Distension & 3 Vomiting & 1 Weight loss & 1 Multiple pain & & Vomiting \\
\hline & 1 Weight loss & 3 Distension & $\begin{array}{l}1 \text { Bowel habit } \\
\text { change }\end{array}$ & & & Bruising \\
\hline & 1 Weakness & 2 Weight loss & & & & Neck pain \\
\hline & & 1 Dyspepsia & & & & Seizure \\
\hline & & & & & & Vaginal bleeding \\
\hline & & & & & & Hematuria \\
\hline
\end{tabular}

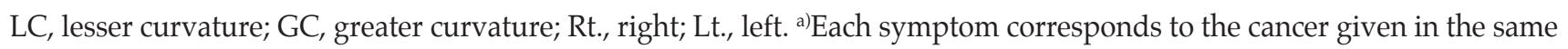
column in the same order, ${ }^{\text {b) }}$ Some patients had many symptoms; all symptoms were counted.

formed. Palliative surgery was performed if necessary, and chemotherapy or RT was performed as indicated. In patients without distant metastasis, curative intent surgery was performed, and adjuvant chemotherapy or RT was added according to the pathologic results and compliance of each patient.

SPSS ver. 23.0 (IBM Corp., Armonk, NY) was used for statistical analysis. Categorical data are reported as numbers and percentages, while continuous data are reported as medians and ranges. Survival rates were calculated by the Kaplan-Meier method, and the log-rank test was used for comparing curves. $\mathrm{p}$-values $<0.05$ were considered significant. Greenwood formula was used to calculate survival estimates, reported as 5-year survival rate and $95 \%$ confidence interval (CI). Missing values were excluded from the analysis.

\section{Ethical statement}

The institutional review board of Seoul National University Hospital approved the study (1808-129-967), and owing to its retrospective nature, informed consents were waived. All methods used in this study complied with the relevant guidelines and regulations.

\section{Results}

\section{Demographic characteristics}

Table 1 shows the clinical characteristics of all patients. The number of occurrences of GC, CRC, OC, lung cancer, and small bowel cancer was 15, 32, 18, 4, and 1, respectively. The origin of other cancers included head and neck, bile duct, pancreas, uterine cervix, and urinary bladder. AC of unknown origin was also included in the "other" category. Ten patients had cancer at other sites, while head and neck cancer was found in three. There was one occurrence each of cholangiocarcinoma, pancreas, cervix, and bladder cancers, as well as three unknown origin cancers in the brain, spine, and bone marrow, where AC is not normally found. Detailed sites of other cancers are shown in Table 2. Of the 80 patients, 37 $(46.3 \%)$ were male, and the proportion increased to $59.7 \%$ 
Table 3. Clinicopathologic characteristics of individual types of cancer

\begin{tabular}{|c|c|c|c|c|c|c|}
\hline & $\begin{array}{l}\text { Stomach } \\
(n=15)\end{array}$ & $\begin{array}{l}\text { Colon } \\
(n=32)\end{array}$ & $\begin{array}{l}\text { Ovarian } \\
(n=18)\end{array}$ & $\begin{array}{l}\text { Lung } \\
(n=4)\end{array}$ & $\begin{array}{l}\text { Small bowel } \\
\qquad(n=1)\end{array}$ & $\begin{array}{l}\text { Others } \\
(n=10)\end{array}$ \\
\hline Male sex & $7(46.7)$ & $22(68.8)$ & - & $3(75.0)$ & $1(100)$ & $4(40.0)$ \\
\hline Age (yr) & $16(12-17)$ & $15(11-17)$ & $15(10-17)$ & $15.5(13-17)$ & 12 & $14(10-17)$ \\
\hline Family history of cancer & $6(40.0)$ & $8(25.0)$ & 0 & $1(25.0)$ & 0 & $1(10.0)$ \\
\hline \multirow[t]{6}{*}{ PMHx } & $1(6.7)$ & $7(21.9)$ & - & $1(25.0)$ & $1(100)$ & $1(10.0)$ \\
\hline & $\begin{array}{l}1 \text { HLH with } \\
\text { autoimmune } \\
\text { enteropathy }\end{array}$ & UC 1 & & 1 PTC & 1 PJS & $1 \mathrm{BA}$ in $\mathrm{CC}$ \\
\hline & & $1 \mathrm{JP}$ & & & & \\
\hline & & $1 \mathrm{NF}-1$ & & & & \\
\hline & & 1 LBS & & & & \\
\hline & & 3 FAP & & & & \\
\hline Symptom duration (mo) & $1.0(0.2-24.4)$ & $1.9(0.3-29.4)$ & $1.9(0.7-34.4)$ & $2.4(1.8-2.9)$ & 2.0 & $2.2(0.7-24.5)$ \\
\hline Size $(\mathrm{cm})$ & $4.0(0.0-8.0)$ & $5.0(0.7-17.0)$ & $20.0(12.0-40.0)$ & $6.5(0.6-6.7)$ & 14.5 & $3.0(0.5-5.0)$ \\
\hline \multicolumn{7}{|l|}{ Operation } \\
\hline R0 & 7 & 13 & 18 & 2 & 1 & 5 \\
\hline $\mathrm{R} 1$ & 0 & 0 & 0 & 0 & 0 & 3 \\
\hline $\mathrm{R} 2$ & 0 & 1 & 0 & 0 & 0 & 0 \\
\hline Palliative & 2 & 12 & 0 & 1 & 0 & 1 \\
\hline No & 6 & 5 & 0 & 0 & 0 & 0 \\
\hline \multicolumn{7}{|l|}{ Differentiation } \\
\hline WD & 0 & 5 & 7 & 0 & 1 & 0 \\
\hline MD & 2 & 11 & 4 & 0 & 0 & 1 \\
\hline PD & 10 & 8 & 0 & 1 & 0 & 1 \\
\hline \multicolumn{7}{|l|}{ Lymphovascular invasion } \\
\hline Yes & 1 & 12 & 1 & 0 & 0 & 0 \\
\hline No & 3 & 11 & 13 & 1 & 1 & 3 \\
\hline \multicolumn{7}{|l|}{ Perineural invasion } \\
\hline Yes & 3 & 7 & 0 & 0 & - & 2 \\
\hline No & 1 & 7 & 9 & 1 & - & 2 \\
\hline \multicolumn{7}{|l|}{ Stage } \\
\hline 1 & 3 & 3 & 17 & 1 & 0 & 3 \\
\hline 2 & 1 & 5 & 0 & 0 & 1 & 1 \\
\hline 3 & 3 & 7 & 1 & 1 & 0 & 0 \\
\hline 4 & 8 & 16 & 0 & 1 & 0 & 5 \\
\hline Chemotherapy & $7(46.7)$ & $24(75.0)$ & $13(72.2)$ & $2(50.0)$ & $1(100)$ & $2(20.0)$ \\
\hline Radiation therapy & 0 & $4(12.5)$ & $1(5.6)$ & $1(25.0)$ & 0 & $4(40.0)$ \\
\hline Recurrence & $2(28.6)$ & $3(21.4)$ & $4(22.2)$ & 0 & $1(100)$ & $1(12.5)$ \\
\hline 5-Year survival rate $(\%)$ & 58.2 & 41.5 & 87.5 & - & - & 64.0 \\
\hline
\end{tabular}

Values are presented as number (\%) or median (range). $\mathrm{PMHx}$, past medical history; $\mathrm{HLH}$, hemophagocytic lymphohistiocytosis; FAP, familial adenomatous polyposis; UC, ulcerative colitis; JP, juvenile polyposis; NF-1, neurofibromatosis type 1; LBS, Louis-Bar syndrome; FAP, familial adenomatous polyposis; PTC, papillary thyroid cancer; PJS, Peutz-Jeghers syndrome; $\mathrm{BA}$, biliary atresia; $\mathrm{CC}$, cholangiocarcinoma; $\mathrm{WD}$, well differentiated; $\mathrm{MD}$, moderately differentiated; $\mathrm{PD}$, poorly differentiated.

when the 18 OC patients were excluded. The median age was 15 years (range, 10 to 17 years). As age increased, the number of patients tended to increase, with 19, 28, and 33 cases aged $10-13,14-15$, and $16-17$ years, respectively. The median symp- tom duration was 1.8 months (range, 0.2 to 34.4 months). The number of patients with stages $1-4$ cancer was $27,8,12$, and 30, respectively. Forty-nine patients $(61.3 \%)$ underwent chemotherapy and $10(12.5 \%)$ underwent RT. The median 
Table 4. Chemotherapy and radiation therapy

\begin{tabular}{|c|c|c|c|c|c|c|}
\hline & $\begin{array}{l}\text { Stomach } \\
(n=15)\end{array}$ & $\begin{array}{l}\text { Colon } \\
(n=32)\end{array}$ & $\begin{array}{l}\text { Ovarian } \\
(n=18)\end{array}$ & $\begin{array}{l}\text { Lung } \\
(n=4)\end{array}$ & $\begin{array}{l}\text { Small bowel } \\
\qquad(\mathbf{n}=\mathbf{1})\end{array}$ & $\begin{array}{l}\text { Others } \\
(n=10)\end{array}$ \\
\hline Chemotherapy & 7 & 24 & 13 & 2 & 1 & 2 \\
\hline Neoadjuvant & 0 & 1 & 1 & 0 & 0 & 0 \\
\hline Adjuvant & 4 & 12 & 13 & 2 & 1 & 1 \\
\hline Palliative & 3 & 13 & 0 & 0 & 0 & 1 \\
\hline \multirow[t]{4}{*}{ Detailed regimen } & FP & FOLFOX & T-CDDP & - & - & Cisplatin $^{\text {a) }}$ \\
\hline & DP & FOLFIRI & CDDP & & & \\
\hline & Doxifluridine & XELOX & & & & \\
\hline & & FL & & & & \\
\hline Radiation therapy & - & 4 & 1 & 1 & - & 4 \\
\hline \multirow[t]{4}{*}{ Location, dose } & & Head & Pelvis, 20 Gy & $\begin{array}{l}\text { Left femur and } \\
\text { spine, } 60 \text { Gy }\end{array}$ & & Brain, 30 Gy \\
\hline & & Spine & & & & Spine, 45 Gy \\
\hline & & Brain, 18Gy & & & & Pelvis, 50 Gy \\
\hline & & Abdomen & & & & Abdomen, 65 Gy \\
\hline
\end{tabular}

FP, 5-fluorouracil and cisplatin; DP, docetaxcel and cisplatin; FOLFOX, folinic acid, fluorouracil and oxaliplatin; FOLFIRI, folinic acid, fluorouracil and irinotecan; XELOX, capecitabine and oxaliplatin; FL, 5-fluorouracil and leucovorin; T-CDDP, paclitaxel and cisplatin; CDDP, cisplatin. ${ }^{a}$ Cisplatin: unknown origin.

Table 5. Tumor markers according to the cancer diagnosis

\begin{tabular}{|c|c|c|c|c|c|c|}
\hline Tumor marker & $\begin{array}{l}\text { Stomach } \\
(n=15)\end{array}$ & $\begin{array}{l}\text { Colon } \\
(n=32)\end{array}$ & $\begin{array}{c}\text { Ovarian } \\
(n=18)\end{array}$ & $\begin{array}{l}\text { Lung } \\
(n=4)\end{array}$ & $\begin{array}{l}\text { Small bowel } \\
\qquad(n=1)\end{array}$ & $\begin{array}{l}\text { Others } \\
(n=10)\end{array}$ \\
\hline \multicolumn{7}{|l|}{ CEA } \\
\hline Available & 9 & 23 & 10 & 1 & 1 & 1 \\
\hline Median (range, $\mathrm{ng} / \mathrm{mL}$ ) & $1.4(0.1-52.1)$ & $5.2(0.1-15,190)$ & $0.95(0.2-18.9)$ & 1 & 0.3 & 1.1 \\
\hline \multicolumn{7}{|l|}{ CA $19-9$} \\
\hline Available & 8 & 10 & 11 & 0 & 1 & 2 \\
\hline Median (range, U / mL) & $8.1(1.9-106.0)$ & $74.2(11.3-1,980)$ & $5.0(0.1-16,050)$ & - & 4.6 & $17.9(4.6-31.2)$ \\
\hline
\end{tabular}

CEA, carcinoembryonic antigen; CA 19-9, cancer antigen 19-9.

follow-up period was 2.0 years (range, 0 to 20.4 years).

\section{Diagnosis-based clinicopathologic characteristics}

Table 3 shows the clinicopathologic characteristics according to diagnosis. The number of patients with a positive family history was six (40.0\%) for GC, eight $(25.0 \%)$ for CRC, one $(25.0 \%)$ for lung cancer, and one $(10.0 \%)$ for other cancers. Seven CRC patients had underlying disease; three had familial adenomatous polyposis (FAP), and one each had ulcerative colitis, juvenile polyposis (JP), neurofibromatosis type 1 (NF-1), and Louis-Bar syndrome. One patient each with GC, lung cancer, small bowel cancer, and cholangiocarcinoma had underlying disease. Median symptom duration ranged between 1.0 and 2.4 months. Abdominal pain was the most common symptom in GC and CRC $(60.0 \%$ in GC, $62.5 \%$ in $\mathrm{CRC})$. The most common feature of OC was abdominal distension (72.2\%). Most masses in GC (53.3\%, 8/15) were located in the gastric body. Detailed locations of each cancer are shown in Table 2. Tumor size was the largest in ovarian cancer (median, $20 \mathrm{~cm}$; range, 12.0 to $40.0 \mathrm{~cm}$ ). R0 resection was achieved in all OC patients. Less than $50 \%$ of patients achieved R0 resection in GC and CRC (46.7\% in GC, $40.6 \%$ in CRC). Of GC patients, $83.3 \%(10 / 12)$ were poorly differentiated (PD), compared to $33.3 \%(8 / 24)$ of CRC patients. Overall, 52.2\% (12/23) CRC patients and 7.1\% (1/14) OC patients were positive for lymphovascular invasion. Nine OC patients were negative for perineural invasion, but $50 \%$ (7/14) of CRC patients were positive. Less than $10 \%$ of patients with CRC had stage 1 disease (9.4\%); $20 \%$ and $94.4 \%$ 
Table 6. Histologic type and lymph node status

\begin{tabular}{lcccccc} 
& $\begin{array}{c}\text { Stomach } \\
(\mathbf{n}=\mathbf{1 5})\end{array}$ & $\begin{array}{c}\text { Colon } \\
(\mathbf{n}=\mathbf{3 2})\end{array}$ & $\begin{array}{c}\text { Ovarian } \\
(\mathrm{n}=\mathbf{1 8})\end{array}$ & $\begin{array}{c}\text { Lung } \\
(\mathbf{n}=\mathbf{4})\end{array}$ & $\begin{array}{c}\text { Small bowel } \\
(\mathbf{n}=\mathbf{1})\end{array}$ & $\begin{array}{c}\text { Others } \\
(\mathbf{n}=\mathbf{1 0})\end{array}$ \\
\hline Histology & 14 & 23 & 18 & 3 & 1 & 10 \\
\hline Adenocarcinoma & 8 & 11 & - & 2 & 1 & 6 \\
\hline Tubular & 1 & - & - & - & - & - \\
\hline Papillary & - & 1 & - & - & - & - \\
\hline Mucinous & - & 7 & 17 & - & - & 2 \\
\hline Serous & - & - & 1 & - & - & - \\
\hline PCC & 5 & 4 & - & - & - & - \\
\hline Others & - & - & - & 1 & - & 2 \\
\hline Lymph node status & 6 & 22 & 7 & 1 & 1 & 4 \\
\hline Retrieval ${ }^{2)}$ & $39.5(22-48)$ & $31(1-138)$ & $16(4-29)$ & 10 & 3 & $9.5(4-10)$ \\
\hline Positive & $3.5(0-9)$ & $2(0-24)$ & $0(0-0)$ & 4 & 0 & $0(0-4)$ \\
\hline
\end{tabular}

Values are presented as number or median (range). PCC, poorly cohesive carcinoma. ${ }^{\text {a)Under }} 12$ lymph node retrievals occurred in 2, 1, and 8 patients of stomach, colon, and ovary cancer, respectively.

of GC and OC were stage 1, respectively. As shown in Table 4, seven GC patients received chemotherapy (in the adjuvant setting for four patients and palliative setting for 3 ), while 4 CRC patients underwent RT. Irradiation sites included the head, spine, brain, and abdominal cavity (Table 4).

\section{Tumor markers and pathology}

Two tumor markers (carcinoembryonic antigen [CEA] and cancer antigen 19-9 [CA 19-9]), were investigated. CEA and CA 19-9 results were available for nine and eight GC patients, respectively. The median CEA and CA 19-9 values were $1.4 \mathrm{ng} / \mathrm{mL}$ (range, 0.1 to $52.1 \mathrm{ng} / \mathrm{mL}$ ) and $8.1 \mathrm{U} / \mathrm{mL}$ (range, 1.9 to $106.0 \mathrm{U} / \mathrm{mL}$ ), respectively. The results for other cancers are shown in Table 5.

Furthermore, $35.7 \%$ of GC (5/14) and $17.4 \%$ of CRC (4/23) patients exhibited poorly cohesive carcinoma. Regarding CRC, $30.4 \%$ were mucinous AC, and $94.4 \%$ of the OC cases $(17 / 18)$ were mucinous cystadenocarcinoma (Table 6). Of the 32 CRC patients, 22 were available for lymph node retrieval and had data concerning lymph node metastasis. The median number of retrieved lymph nodes and metastatic lymph nodes was 31 (range, 1 to 138) and 2 (range, 0 to 24), respectively. The results for other cancers are shown in Table 6.

\section{Survivals and prognostic factors}

The 5-year overall survival estimate was $57.9 \% \pm 11.5 \%$ for all patients (Fig. 1A), and $58.2 \% \pm 25.7 \%, 41.5 \% \pm 18.2 \%, 87.5 \% \pm$ $16.2 \%$, and $64.0 \% \pm 34.4 \%$ for GC, CRC, OC, and other cancers, respectively (Fig. 1B). The 5-year survival rate following $\mathrm{R} 0$ resection was $88.7 \%$. All three patients with $\mathrm{R} 1$ resection sur- vived, and one patient with $\mathrm{R} 2$ resection died after 8 months of diagnosis. None of the patients with palliative operation or inoperable status was long-term survivor (Fig. 1C). The 5-year survival rate for stages 1 and 3 were $96 \%$ and $56.3 \%$, respectively. All seven patients with stage 2 cancer were alive at the last follow-up. The longest survival for patients with stage 4 disease was 3.4 years and the 5 -year survival rate was $8.4 \%$ (Fig. 1D). The 5-year survival rate was $97.0 \% \pm 3.0 \%$ and $21.0 \% \pm 7.6 \%$ for stage 1 or 2 and 3 or $4(p<0.001)$. GC, CRC, small bowel cancer, pancreatic cancer, and cholangiocarcinoma were grouped as gastrointestinal (GI) cancer while other cancers (ovary, lung, and unknown origin tumor) were grouped as non-GI cancer. The overall survival differed significantly between the two groups (5-year survival GI, 44.7\%; non-GI, 78.8\%; $\mathrm{p}=0.007$ ) (Fig. 2). The survival rate was calculated to examine the prognostic value of CEA in 45 patients. The 5-year survival rate in patients with CEA levels $<3$ and $>3 \mathrm{ng} / \mathrm{mL}$ was $69.3 \%$ and $23.8 \%$, respectively (Fig. 3 ). The effects of GI cancer and CEA level were adjusted in the multivariable analysis. CEA level was the only factor influencing survival (hazard ratio, 3.587; 95\% CI, 1.347 to 9.552; $\mathrm{p}=0.01$ ) (S1 Table, Supplementary Materials).

\section{Subgroup analysis}

The effects of underlying disease on the stage were analyzed in CRC patients. There was no statistical difference in stage distribution between the patients with and without underlying disease (S2 Table, Supplementary Materials). Advanced stage patients were analyzed for differences in survival rates depending on whether chemotherapy was performed or not. Survivals were not significantly different in 
A

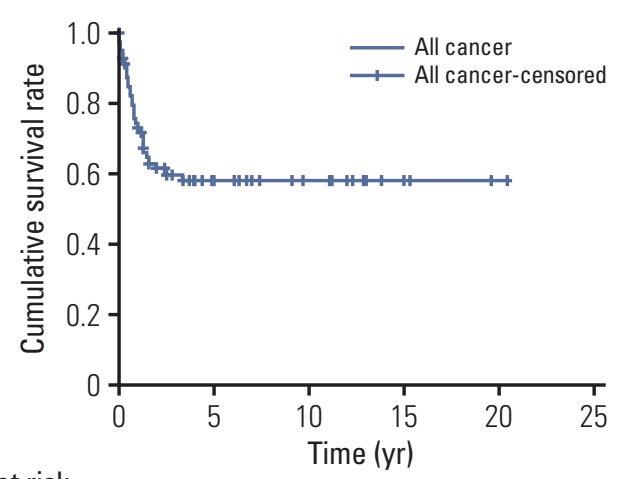

No. at risk
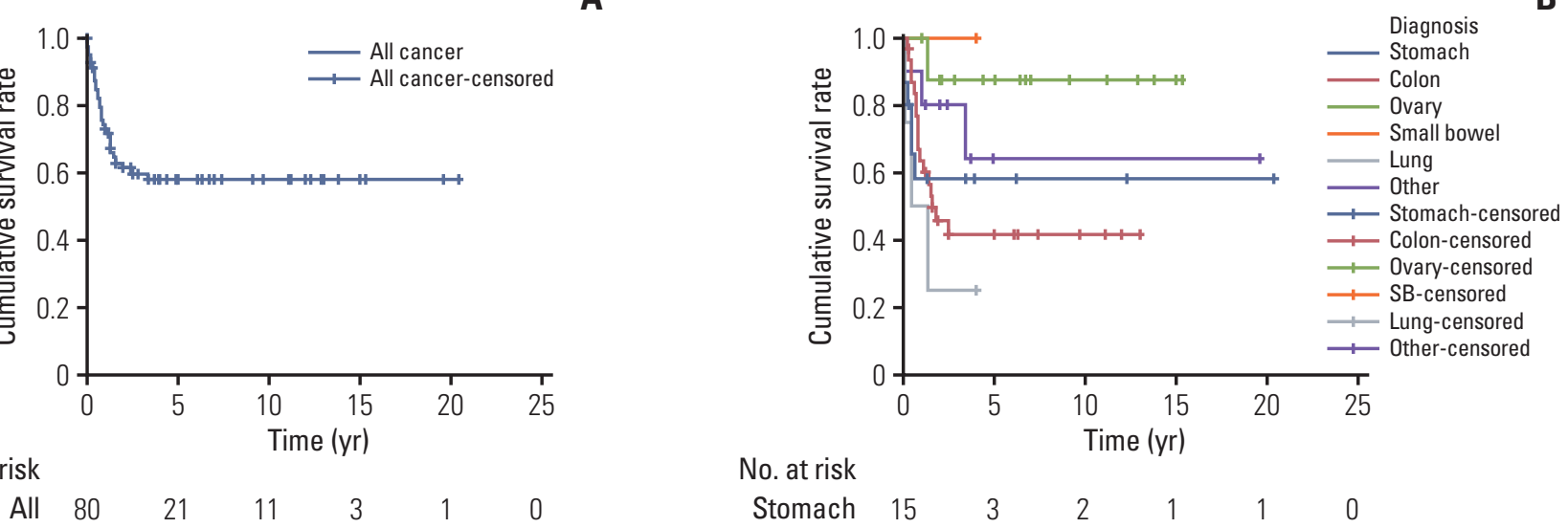

No. at risk

$\begin{array}{rrrrrrr}\text { Stomach } & 15 & 3 & 2 & 1 & 1 & 0 \\ \text { Colon } & 32 & 8 & 3 & 0 & 0 & 0 \\ \text { Ovary } & 18 & 9 & 5 & 1 & 0 & 0 \\ \text { SB } & 1 & 0 & 0 & 0 & 0 & 0 \\ \text { Lung } & 4 & 0 & 0 & 0 & 0 & 0 \\ \text { Other } & 10 & 1 & 1 & 1 & 0 & 0\end{array}$

C

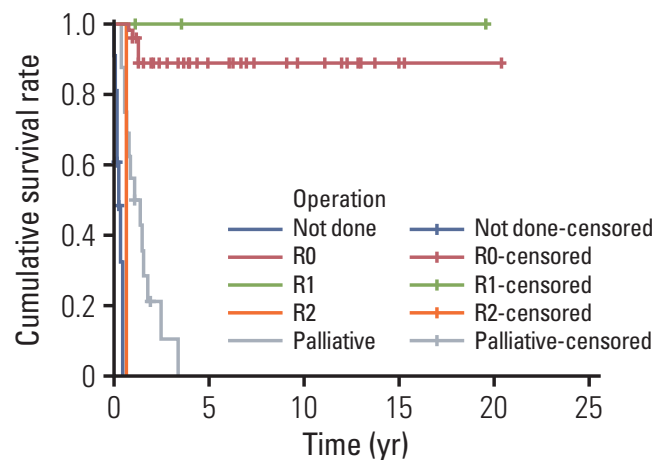

No. at risk

$\begin{array}{rrrrrrr}\text { Not done } & 11 & 0 & 0 & 0 & 0 & 0 \\ \text { R0 } & 46 & 20 & 10 & 2 & 1 & 0 \\ \text { R1 } & 3 & 1 & 1 & 1 & 0 & 0 \\ \text { R2 } & 1 & 0 & 0 & 0 & 0 & 0 \\ \text { Palliative } & 16 & 0 & 0 & 0 & 0 & 0\end{array}$

No. at risk

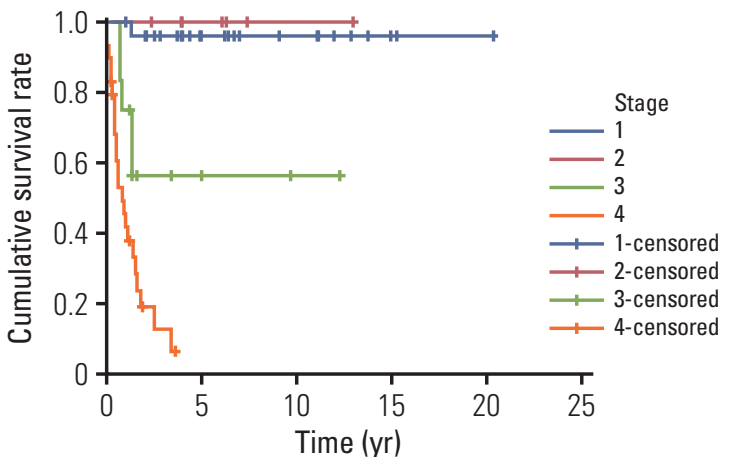

Fig. 1. (A) Survival distribution of all 80 patients. The 5-year overall survival rate was 57.9\%. (B) Survival distribution according to the diagnosis. (C) Survival distribution according to the resection type. (D) Survival distribution according to the stage. The number of survival periods represents the year for each figure.

the patients with and without chemotherapy (5-year survival rates $18.8 \%$ and $24.2 \%$ respectively, $\mathrm{p}=0.263$ ) (S3 Fig., Supplementary Materials).

\section{Discussion}

This study was a clinical series of AC, an extremely rare disease entity, including relatively large GC and OC, in children and adolescents. Despite its rarity, it is evident that a variety of ACs occurred in children and adolescents. The specific tumor locations were the stomach, colon and rectum, ovary, lung, small bowel, oral cavity, nasal cavity, parotid 


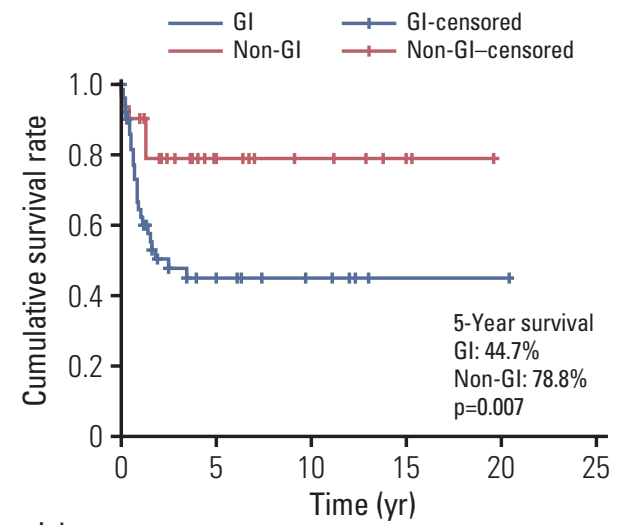

No. at risk

$\begin{array}{rrrrrrr}\text { GI } & 50 & 11 & 4 & 1 & 1 & 0 \\ \text { Non-GI } & 30 & 10 & 6 & 2 & 0 & 0\end{array}$

Fig. 2. Comparison of overall survival between the groups with gastrointestinal cancer (GI) and without GI (non-GI). The number of survival periods represents the year. GI, gastrointestinal cancers (gastric cancer, colorectal cancer, small bowel cancer, pancreatic cancer, cholangiocarcinoma); Non-GI, all cancers except for the abovementioned cancers.

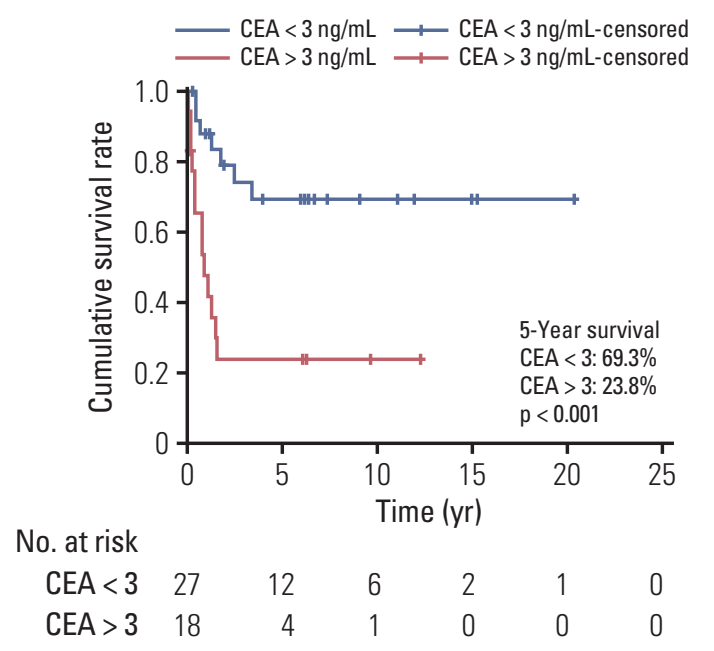

Fig. 3. Comparison of survival in patients with carcinoembryonic antigen (CEA) level $<3 \mathrm{ng} / \mathrm{mL}$ and $>3 \mathrm{ng} / \mathrm{mL}$. The value for the survival period represents the year.

gland, pancreatic duct, urinary bladder, and uterine cervix. Cancer of unknown origin was also identified. Regardless of the cancer type, the ages at diagnosis were similar. Almost half of all patients $(n=33)$ had a $>2$-month delay from initial symptom onset to diagnosis. Approximately $40 \%$ of GC and
CRC patients had a positive family history. About half of the GC and CRC patients were diagnosed with distant metastasis. OC tumor size was relatively large, but most cases presented at an early stage. Regardless of the family history of $\mathrm{AC}$, diagnosis of pediatric $\mathrm{AC}$ was relatively delayed, with a tendency of diagnosis at an advanced stage.

GI tumors comprised $<5 \%$ of all malignancies in children. Of these, less than $0.05 \%$ were primary gastric carcinoma [19]. Among 15 patients in our study, six (40\%) had a family history of cancer, among whom, three had relatives who died of GC. Median symptom duration was 1 month in GC. Maconi et al. [20] reported a mean symptom duration of 16.8 weeks with alarming symptoms and 29.3 weeks with no alarming symptoms in GC patients aged $<45$ years. These results are comparable to ours, although several bias may exist in the comparison between the previous study and ours. For example, because patients in our study were children or adolescents; they could neither remember the exact time of initial symptoms, nor the necessity of going to the hospital. It is known that cancer is usually found at a later stage in children compared to adults [21]. To compare the pediatric GC survivals between our study and previous ones, 36 patients in 22 case reports or series were identified, and the 5-year survival rate was found to be $8.4 \%$ (S4 Fig., Supplementary Materials). Due to the heterogeneity of the included studies and the evolution of treatment during the studies, it is difficult to directly compare the survival rates in these studies and ours. Except two patients who showed general weakness and weight loss, the majority of symptoms were nonspecific, such as abdominal pain, indigestion, or vomiting. Hence, if symptoms persist for a long time, although they may appear negligible, thorough examinations may be necessary.

GI cancer is the most frequent form of hereditary neoplasia, and approximately $10 \%-20 \%$ of CRCs in children and adolescents occur in those with familial history $[11,22]$. In our study, eight CRC patients (25\%) had a family history of cancer, and this is well correlated with values from other studies. Overall, 3\%-5\% of the population had specific underlying predisposing conditions, including inflammatory bowel disease, Peutz-Jeghers syndrome, JP, hereditary mixed polyposis syndrome, hereditary non-polyposis colon cancer (HNPCC), and FAP $[5,13]$. Among these, HNPCC is associated with the highest risk [5]. In our study, seven (21.9\%) patients had underlying disease, a proportion that is higher than that previously reported. Not only well-known underlying disease, but also NF-1 and Louis-Bar syndrome were included. Zoller et al. [23] reported four CRCs in 70 NF-1 patients during 11year follow-up. There was one published pediatric AC case with NF-1 [24]. One CRC patient in this study who had Louis-Bar syndrome, also called ataxia-telangiectasia, was previously reported [25]. Non-Hodgkin lymphoma and solid 
tumors can occur, but CRC is a rare cancer in ataxia-telangiectasia.

Decreased appetite and weight loss, changes in bowel habits, and rectal bleeding with changes in stool caliber may be observed in CRC patients [13]. In our study, nonspecific symptoms were common, but hematochezia and weight loss accounted for $28.1 \%$ of symptoms. Some authors reported a symptom duration of $>10$ weeks in adult CRC $[26,27]$; this appears to be shorter than that in pediatric CRC in this study. Most CRCs in adults are moderately differentiated (MD) or well differentiated (WD) ACs. In contrast, more than half of reported childhood CRC cases are PD mucinous ACs, many of which are of the signet-ring cell type [13]. In our study, there were five WD, $11 \mathrm{MD}$, and eight PD cases. Mucinous type accounted for $21.9 \%$ and poorly cohesive cancer for $12.5 \%$. Long-term survival rates in pediatric CRC patients were $20 \%-50 \%$ in other studies $[4,9,11]$, and $41.5 \%$ in ours. Sultan et al. [28] reported only on 159 children/adolescent CRC patients through the Surveillance, Epidemiology, and End Results database from 1973 to 2005 . They also confirmed the poor prognostic features of pediatric CRC (i.e., mucinous $\mathrm{AC}$ and signet ring cell carcinoma). The 5-year survival estimate in that study $(40 \% \pm 4.2 \%)$, was comparable with our result $(41.5 \% \pm 18.2 \%)$. This low survival rate of CRC seems to be associated with the pathologic feature of poor differentiation.

Epithelial neoplasms are the most frequent histological type in adult OCs, while in childhood and adolescence, the majorities are non-epithelial and of germ cell origin [7,29]. In our study, 17 cases were of mucinous type and one was of the serous type.

One female patient with lung cancer in this study was treated for papillary thyroid cancer prior to the diagnosis of lung cancer. Three years before she was diagnosed with lung cancer, she received a cumulative of $350 \mathrm{mCi}$ radioactive iodine ablation in a year. Teng et al. [30] reported that the risk of secondary cancer increases when the cumulative radiation exceeds $150 \mathrm{mCi}$, and a 2.14-fold increase is noted in female lung cancer patients. Rojas et al. [31] reported on 211 children with malignant pulmonary tumors using the National Cancer Database. Of these, 16 ACs were identified, and their 5-year survival rate was $26 \%$. Childhood pulmonary $\mathrm{AC}$ is so rare in Korea, that only few case reports have been published so far [15].

Yoon et al. [32] reported the occurrence of cholangiocarcinoma in a patient who previously underwent Kasai operation (owing to biliary atresia). Cholangiocarcinoma arising in biliary atresia patients with non-surgical treatment was also reported [33].

Since little is known about the treatment for pediatric AC, the treatment principles follows those in adult AC according to previously reported articles [3,8]. Hill et al. [8], in a review on pediatric $\mathrm{CRC}$, reported chemotherapy and RT. Subbiah et al. [3] reported the use of platinum-based agent and 5-fluorouracil in pediatric GC and bevacizumab was used in one patient. In the present study, 5-fluorouracil and platinumbased agent were used as the first line chemotherapy in CRC. There were also cases where bevacizumab was added. However, there was no benefit with the chemotherapy, and this was thought to be due to the large number of patients with advanced stage.

The usefulness of CEA for prognosis in pediatric AC has rarely been investigated. One study investigated the role of CEA in detecting recurrence after surgery for CRC, in 11 pediatric patients [34]. Sensitivity and specificity for recurrence detection in CRC was $64 \%$ and $77 \%$, respectively. This result suggests the value of CEA as an independent prognostic factor, but this requires more prospective studies.

This study has several limitations. Although this was a multicenter study, we did not include all pediatric AC cases in the country during the study period, mainly because the only institutions with pediatric surgery participated in this study. Thus, it was not possible to determine the national AC incidence. Comparison with adult AC was impossible due to the study design and the lack of pediatric AC results. Survival analysis based on examined factors was not performed. During 20 years of enrollment, the staging system had changed, and treatment modality had greatly evolved; thus, the data may not truly reflect this change. Further, the biggest limitation may be the lack of molecular studies, underlying genetic pathogenesis, and the use of the latest tumor markers. However, despite these limitations, the analysis of many clinical features of pediatric ACs, including several GC cases, makes our study findings valuable.

ACs in pediatric patients arise from various organs and are often diagnosed at advanced stages because of its rarity or the characteristics of children. Family history of cancer or underlying disease relevant to malignancy was positive for $30 \%$. Overall 5-year survival rate for all ACs was 57.9\%. ACs that originated from GI and CEA level $>3 \mathrm{ng} / \mathrm{mL}$ at diagnosis are poor prognosis factors for pediatric ACs. Because AC is extremely rare in pediatric population, more large prospective multicenter studies on the treatment and prognosis are warranted for further understanding and better survival of this malignancy.

\section{Electronic Supplementary Material}

Supplementary materials are available at Cancer Research and Treatment website (https: // www.e-crt.org).

\section{Conflicts of Interest}

Conflict of interest relevant to this article was not reported. 


\section{Author Details}

${ }^{1}$ Department of Pediatric Surgery, Seoul National University Children's Hospital, Seoul, '2Department of Pediatric Surgery, Asan Medical Center Children's Hospital, University of Ulsan College of Medicine, Seoul, ${ }^{3}$ Department of Surgery, Haeundae Paik Hospital, Inje University College of Medicine, Busan, ${ }^{4}$ Department of Surgery, Kyungpook National University Hospital, School of Medicine, Kyungpook National University, Daegu, 5epartment of Surgery, Chonbuk National University School of Medicine, Jeonju, ${ }^{6}$ Department of Surgery, Samsung Medical Center, Sungkyunkwan Univer- sity School of Medicine, Seoul, 'Department of Pediatrics, Samsung Medical Center, Sungkyunkwan University School of Medicine, Seoul, ${ }^{8}$ Department of Pediatric Surgery, Seoul National University College of Medicine, Seoul, 'Department of Pediatric Surgery, Seoul St. Mary's Hospital, College of Medicine, The Catholic University of Korea, Seoul, ${ }^{10}$ Department of Pediatric Surgery, Inha School of Medicine, Incheon, ${ }^{11}$ Department of Surgery, Ilsan Paik Hospital, Inje University, Goyang, ${ }^{12}$ Department of Pediatric Surgery, Severance Children's Hospital, Yonsei University College of Medicine, Seoul, Korea

\section{References}

1. Kaatsch P. Epidemiology of childhood cancer. Cancer Treat Rev. 2010;36:277-85.

2. Park HJ, Moon EK, Yoon JY, Oh CM, Jung KW, Park BK, et al. Incidence and survival of childhood cancer in Korea. Cancer Res Treat. 2016;48:869-82.

3. Subbiah V, Varadhachary G, Herzog CE, Huh WW. Gastric adenocarcinoma in children and adolescents. Pediatr Blood Cancer. 2011;57:524-7.

4. Chantada GL, Perelli VB, Lombardi MG, Amaral D, Cascallar $\mathrm{D}$, Scopinaro M, et al. Colorectal carcinoma in children, adolescents, and young adults. J Pediatr Hematol Oncol. 2005;27: 39-41.

5. Durno C, Aronson M, Bapat B, Cohen Z, Gallinger S. Family history and molecular features of children, adolescents, and young adults with colorectal carcinoma. Gut. 2005;54:1146-50.

6. Hatzaras I, Palesty JA, Abir F, Sullivan P, Kozol RA, Dudrick SJ, et al. Small-bowel tumors: epidemiologic and clinical characteristics of 1260 cases from the connecticut tumor registry. Arch Surg. 2007;142:229-35.

7. Menczer J, Sadetzki S, Murad H, Barda G, Andreev H, Barchana M. Childhood and adolescent ovarian malignant tumors in Israel: a nationwide study. Acta Obstet Gynecol Scand. 1999;78:813-7.

8. Hill DA, Furman WL, Billups CA, Riedley SE, Cain AM, Rao $\mathrm{BN}$, et al. Colorectal carcinoma in childhood and adolescence: a clinicopathologic review. J Clin Oncol. 2007;25:5808-14.

9. Pratt CB, Rivera G, Shanks E, Johnson WW, Howarth C, Terrell $\mathrm{W}$, et al. Colorectal carcinoma in adolescents implications regarding etiology. Cancer. 1977;40(5 Suppl):2464-72.

10. Karnak I, Ciftci AO, Senocak ME, Buyukpamukcu N. Colorectal carcinoma in children. J Pediatr Surg. 1999;34:1499-504.

11. Ferrari A, Rognone A, Casanova M, Zaffignani E, Piva L, Collini $\mathrm{P}$, et al. Colorectal carcinoma in children and adolescents: the experience of the Istituto Nazionale Tumori of Milan, Italy. Pediatr Blood Cancer. 2008;50:588-93.

12. Takeyama E, Tanaka M, Fujishiro J, Kitagawa N, Iwanaka T, Tanaka Y. A case of alpha-fetoprotein-producing gastric cancer in a child presenting with rupture of multiple liver metas- tases. Pediatr Surg Int. 2015;31:885-8.

13. Al-Tonbary Y, Darwish A, El-Hussein A, Fouda A. Adenocarcinoma of the colon in children: case series and mini-review of the literature. Hematol Oncol Stem Cell Ther. 2013;6:29-33.

14. Blumer SL, Anupindi SA, Adamson PC, Lin H, Price AP, Markowitz RI, et al. Sporadic adenocarcinoma of the colon in children: case series and review of the literature. J Pediatr Hematol Oncol. 2012;34:e137-41.

15. Park JA, Park HJ, Lee JS, Ha JO, Lee GK, Park BK, et al. Adenocarcinoma of lung in never smoked children. Lung Cancer. 2008;61:266-9.

16. Pasternak BA, Kaistha A. Jejunal adenocarcinoma: a rare cause of chronic anemia in children. J Pediatr Gastroenterol Nutr. 2006;42:100-3.

17. Michalek J, Kopecna L, Tuma J, Hrstkova H, Feit J. Gastric carcinoma in a 9-year-old boy. Pediatr Hematol Oncol. 2000;17: 511-5.

18. Lamego CM, Torloni H. Colorectal adenocarcinoma in childhood and adolescent: report of 11 cases and review of the literature. Pediatr Radiol. 1989;19:504-8.

19. Goldthorn JF, Canizaro PC. Gastrointestinal malignancies in infancy, childhood, and adolescence. Surg Clin North Am. 1986;66:845-61.

20. Maconi G, Kurihara H, Panizzo V, Russo A, Cristaldi M, Marrelli D, et al. Gastric cancer in young patients with no alarm symptoms: focus on delay in diagnosis, stage of neoplasm and survival. Scand J Gastroenterol. 2003;38:1249-55.

21. MedlinePlus Medical Encyclopedia. How childhood cancers are different from adult cancers [Internet]. Bethesda, MD: U.S. National Library of Medicine; 2019 [cited 2019 Apr 28]. Available from: https://medlineplus.gov/ency/patientinstructions/ 000845.htm.

22. Fearon ER. Human cancer syndromes: clues to the origin and nature of cancer. Science. 1997;278:1043-50.

23. Zoller ME, Rembeck B, Oden A, Samuelsson M, Angervall L. Malignant and benign tumors in patients with neurofibromatosis type 1 in a defined Swedish population. Cancer. 1997;79:2125-31. 
24. Shearer P, Parham D, Kovnar E, Kun L, Rao B, Lobe T, et al. Neurofibromatosis type I and malignancy: review of 32 pediatric cases treated at a single institution. Med Pediatr Oncol. 1994;22:78-83.

25. Jo KM, Yang SY, Park JH, Kim TO, Jeong HJ, Heo CM, et al. Childhood colon cancer in a patient with ataxia telangiectasia. Ann Transl Med. 2016;4:11.

26. Majumdar SR, Fletcher RH, Evans AT. How does colorectal cancer present? Symptoms, duration, and clues to location. Am J Gastroenterol. 1999;94:3039-45.

27. Esteva M, Leiva A, Ramos M, Pita-Fernandez S, GonzalezLujan L, Casamitjana M, et al. Factors related with symptom duration until diagnosis and treatment of symptomatic colorectal cancer. BMC Cancer. 2013;13:87.

28. Sultan I, Rodriguez-Galindo C, El-Taani H, Pastore G, Casanova M, Gallino G, et al. Distinct features of colorectal cancer in children and adolescents: a population-based study of 159 cases. Cancer. 2010;116:758-65.

29. Deprest J, Moerman P, Corneillie P, Ide P. Ovarian borderline mucinous tumor in a premenarchal girl: review on ovarian epithelial cancer in young girls. Gynecol Oncol. 1992;45:219-
24.

30. Teng CJ, Hu YW, Chen SC, Yeh CM, Chiang HL, Chen TJ, et al. Use of radioactive iodine for thyroid cancer and risk of second primary malignancy: a nationwide population-based study. J Natl Cancer Inst. 2016;108:djv314.

31. Rojas Y, Shi YX, Zhang W, Beierle EA, Doski JJ, Goldfarb M, et al. Primary malignant pulmonary tumors in children: a review of the national cancer data base. J Pediatr Surg. 2015; 50:1004-8.

32. Yoon HJ, Jeon TY, Yoo SY, Kim JH, Eo H, Lee SK, et al. Hepatic tumours in children with biliary atresia: single-centre experience in 13 cases and review of the literature. Clin Radiol. 2014;69:e113-9.

33. Kulkarni PB, Beatty E Jr. Cholangiocarcinoma associated with biliary cirrhosis due to congenital biliary atresia. Am J Dis Child. 1977;131:442-4.

34. Angel CA, Pratt CB, Rao BN, Schell MJ, Parham DM, Lobe TE, et al. Carcinoembryonic antigen and carbohydrate 19-9 antigen as markers for colorectal carcinoma in children and adolescents. Cancer. 1992;69:1487-91. 